\title{
Correction to: High-depth resequencing of 312 accessions reveals the local adaptation of foxtail millet
}

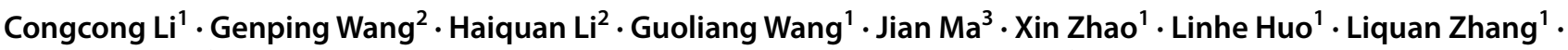 \\ Yanmiao Jiang ${ }^{2}$. Jiewei Zhang ${ }^{1}$. Guiming Liu ${ }^{1}$ - Guoqing Liu ${ }^{2} \cdot$ Ruhong Cheng $^{2}$ · Jianhua Wei ${ }^{1}$ - Lei Yao ${ }^{1}$ (I)
}

Published online: 31 March 2021

(c) Springer-Verlag GmbH Germany, part of Springer Nature 2021

\section{Correction to: Theoretical and Applied Genetics https://doi.org/10.1007/s00122-020-03760-4}

The article "High-depth resequencing of 312 accessions reveals the local adaptation of foxtail millet" written by Jianhua Wei et al was originally published electronically on the publisher's internet portal (currently Springerlink) on February 10, 2021, with open access. With the author(s)' decision to step back from open choice, the copyright of the article was changed (March 2021) to $\odot$ Springer-Verlag GmbH Germany, part of Springer Nature 2021, and the article is forthwith distributed under the terms of copyright.

The original article was corrected.

The original article can be found online at https://doi.org/10.1007/ s00122-020-03760-4.

\section{Jianhua Wei}

weijianhua@baafs.net.cn

$\triangle$ Lei Yao

yaolei@baafs.net.cn

$1 \quad$ Beijing Agro-Biotechnology Research Center, Beijing Key Laboratory of Agricultural Genetic Resources and Biotechnology, Beijing Academy of Agriculture and Forestry Sciences, Beijing 100097, China

2 Institute of Millet Crops, Key Laboratory of Minor Crops in Hebei Province, Hebei Academy of Agriculture and Forestry Sciences, Shijiazhuang 050035, China

3 Beijing Vegetable Research Center, Beijing Key Laboratory of Vegetable Germplasms Improvement, National Engineering Research Center for Vegetables, Beijing Academy of Agriculture and Forestry Science, Beijing 100097, China
Publisher's Note Springer Nature remains neutral with regard to jurisdictional claims in published maps and institutional affiliations. 